\title{
Medication overuse headache: strategies for prevention and treatment using a multidisciplinary approach
}

\author{
Mieke van Driel *, Esther Anderson, Treasure McGuire, Richard Stark
}

\begin{abstract}
A B S T R A C T
Medication overuse headache, which affects patients who have migraines and frequent headaches, is prevalent worldwide and can severely impact daily functioning. Medication overuse headache is often not recognised by primary care physicians or general practitioners, as patients mayoverusemedications that are freely available without a prescription. Overuse of codeine-containing analgesics is particularly problematic and contributes to ongoing morbidity and opioid-related mortality. This article aims to provide an overview of the detection, prevention, and management of medication overuse headache. The definition of medication overuse headache and the risk levels of commonly used symptomatic headache medications are presented. An algorithm consisting of a number of simple questions can assist general practitioners with identifying at-risk patients. Treatment strategies are discussed in the context of a multidisciplinary approach.
\end{abstract}

Hong Kong Med J 2018;24:617-22

DOI: 10.12809/hkmj177024

${ }^{1}$ M van Driel *, MD, PhD

${ }^{2} \mathrm{E}$ Anderson, $\mathrm{MSc}, \mathrm{PhD}$

3,4,5 T McGuire, BPharm, PhD

${ }^{6}$ R Stark, MB, BS, FRACP

${ }^{1}$ Faculty of Medicine, University of Queensland, Brisbane, Queensland, Australia

2 In Vivo Academy Ltd, In Vivo Communications, Sydney, New South Wales, Australia

${ }^{3}$ Faculty of Health Sciences and Medicine, Bond University, Gold Coast, Queensland, Australia

School of Pharmacy, The University of Queensland, Brisbane, Queensland, Australia

${ }^{5}$ Mater Pharmacy Services, Mater Health Services, South Brisbane, Queensland, Australia

${ }^{6}$ Neurology Department, Alfred Hospital, Melbourne, Victoria, Australia

* Corresponding author: m.vandriel@uq.edu.au
The estimated prevalence of medication overuse headache $(\mathrm{MOH})$ in the general population ranges from $0.6 \%$ to $7 \% .^{1-8} \mathrm{~A}$ number of acute headache treatments may cause $\mathrm{MOH},{ }^{7}$ and the medications that are predominantly associated with $\mathrm{MOH}$ vary from country to country. ${ }^{1,7,9,10}$ Opioids such as codeine are particularly problematic, as they are consistently associated with increasingly severe headaches ${ }^{11}$ $\left(\right.$ Table $^{12}$ ) and poor outcomes after withdrawal. ${ }^{13}$ In a number of regions, including Hong Kong and Japan, codeine-containing medication is only available by prescription. ${ }^{14}$ In Australia, beginning in 2018, codeine (and its combinations with simple analgesics) will only be available by prescription, following a 2015 decision by the Australian Therapeutic Goods Administration (TGA). ${ }^{15}$ This policy change is supported by evidence demonstrating an increase in unintentional codeine-related deaths in Australia. ${ }^{16}$

A systematic analysis of the global, regional, and national burden of neurological disorders from 1990 to 2015 (using data from the Global Burden of Disease Study 2015) found that neurological disorders were the leading cause of disabilityadjusted life years (DALYs) in 2015, with the most prevalent neurological disorders being tensiontype headache (1505.9 million DALYs), migraine (958.8 million DALYs), and $\mathrm{MOH}$ (58.5 million DALYs). ${ }^{17}$ As large numbers of people are potentially at risk of $\mathrm{MOH}$, including anyone with frequent primary episodic headaches, strategies for primary prevention, treatment, and prevention of relapse may have substantial public health benefits.

TABLE. Risk of $\mathrm{MOH}$ from symptomatic headache medications ${ }^{12}$

\begin{tabular}{llll}
\hline High risk & Moderate & Low & Negligible \\
\hline - Opioids (eg, codeine-containing medications) & - Triptans & $\bullet$ Simple analgesics (eg, aspirin, paracetamol) & • Long-acting NSAIDs \\
- Caffeine & - Tramadol & - Short-acting NSAIDs & Dihydroergotamine mesylate \\
\hline
\end{tabular}

Abbreviations: $\mathrm{MOH}=$ medication overuse headache; NSAIDs = nonsteroidal anti-inflammatory drugs 


\section{過度使用藥物性頭痛：多學科預防及治療策略}

Mieke van Driel、Esther Anderson、Treasure McGuire 、

Richard Stark

過度使用藥物性頭痛是常見疾病, 對偏頭痛及經常頭痛的患者造成影 響, 甚至會嚴重影響日常功能。由於患者有可能過度使用未經處方且 容易於藥房購買的藥物, 初級保健醫生或全科醫生通常無法識別過度 使用藥物性頭痛患者。過度使用含可卡因的鎮痛藥尤見嚴重, 它可導 致患者持續發病和與鴉片類藥物相關的死亡。本文旨在概述過度使用 藥物性頭痛的檢測、預防和治療, 並介紹過度使用藥物性頭痛的定義 和常用症狀性頭痛藥物的風險水平。由一連串簡單問題組成的算法有 助全科醫生識別風險患者。本文也在多學科方法的背景下討論治療策 略。 were unfamiliar with local clinical practice guidelines about headaches. ${ }^{21}$

Patients with frequent episodic migraines (headaches on 8-15 days per month) or chronic migraines (headaches on $>15$ days per month) are at particular risk of developing $\mathrm{MOH}$. General practitioners play a crucial role in identifying these patients, assessing their medication intake, and offering strategies to minimise the risk of $\mathrm{MOH}$ (Box $\left.1^{4,22}\right)$.

Patients may be reluctant to reveal how many analgesics they take or may be unaware or unwilling to accept that the medication they use to treat their headaches is actually contributing to the continuation of their headaches. They may also be reluctant to discontinue medication that they have found to provide some relief for their headaches in the past. Patients who are anxious about their headaches interfering with essential activities, such as work, may use medication routinely as a preventive measure. In addition, a common misperception among consumers is that medication that can be purchased without a prescription ('over the counter') is harmless. ${ }^{23}$ Unfortunately, once established, $\mathrm{MOH}$ (particularly that caused by opioids) has a high relapse rate after treatment. ${ }^{24}$ Adherence to recommended treatment is generally suboptimal in patients with $\mathrm{MOH}$, but the majority of relapses occur in the first year after withdrawal. ${ }^{25}$ It is therefore important to educate patients about the pathophysiology and treatment of $\mathrm{MOH}$ and to continue supporting them beyond the immediate period of withdrawal.

Some patients who report "excessive" medication use and very frequent headache do not respond to medication withdrawal. Patients who develop $\mathrm{MOH}$ are usually those with intrinsically high-frequency headaches, and withdrawal tends to lead to reversion to their natural background headache pattern, which may range from infrequent episodic migraines to higher-frequency patterns. Scher et $\mathrm{a}^{26}$ questioned the benefit of withdrawal or restriction of medication on the grounds that the patient may not benefit from it. However, withdrawal allows the underlying headache pattern to be determined and a reappraisal of headache control to be conducted. Study results have demonstrated that withdrawal of headache medication benefits many patients with $\mathrm{MOH}$. For example, in a recent study, patients diagnosed with $\mathrm{MOH}$ were randomised to 2 months' detoxification with either complete withdrawal of medication or acute medication restricted to 2 days/week. The number of migrainedays/month was significantly reduced after 6 months with both treatments, with a greater reduction of migraine-days/month in the complete withdrawal group, indicating that complete withdrawal is generally more effective than medication restriction 
BOX I. Practical strategies for avoiding $\mathrm{MOH}$

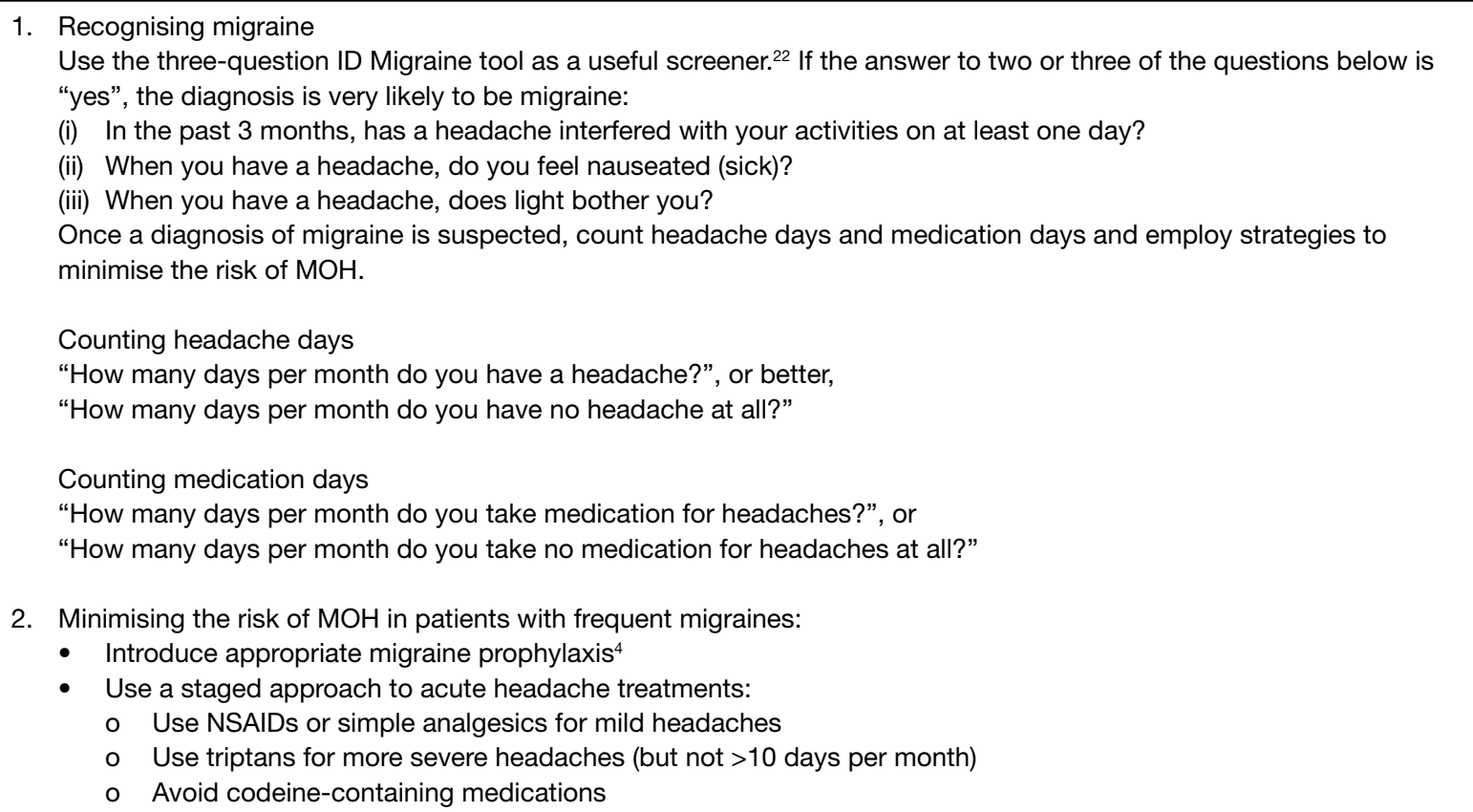

Abbreviations: $\mathrm{MOH}=$ medication overuse headache; NSAIDs = nonsteroidal anti-inflammatory drugs

and that medication overuse was a major factor in the patients' headache pathology. ${ }^{27}$

\section{A multidisciplinary approach}

As patients with $\mathrm{MOH}$ often do not present to their GPs in response to the first instance, pharmacists can play a role in educating patients who selfmedicate with analgesics when analgesics are purchased without a prescription..$^{28}$ They could encourage patients who may be overusing pain relief medication to consult their GPs to discuss other treatment options. However, it may not be easy to identify at-risk patients, as some obtain large quantities of headache medications by shopping at different pharmacies. Identification of these patients could be facilitated by using a tracking system to detect patients who buy headache medication at multiple pharmacies.

Conditions associated with self-medication, such as $\mathrm{MOH}$, could be prevented by community pharmacists. Community pharmacists have overviews of both prescriptions and non-prescription medications that patients are taking (provided that patients are not visiting several different pharmacies) and are easily accessible to patients. ${ }^{29,30}$ Thus, the sale of headache medications is an opportunity to discuss their potential adverse effects and their role in MOH. A survey in Japan on the role of community pharmacists in self-medication of patients with headache found that $32 \%$ of the surveyed doctors were concerned about the increase of patients who overuse headache medication. Both doctors and pharmacists thought that pharmacists should not only provide patients with "instruction on the use of drugs" but also suggest "when to consult a hospital or clinic". ${ }^{31}$ However, strategies may need to be devised to motivate patients to do this, as another Japanese survey of pharmacists and doctors found that $22 \%$ of pharmacists had experienced refusal by patients with headache to consult a clinic, despite the pharmacist's recommendation. ${ }^{32}$

Community pharmacists have an important role in supporting patients with headache. This can be fostered by all key stakeholders-pharmacists, doctors, and patients-being provided with multidisciplinary opportunities to improve their $\mathrm{MOH}$ health literacy and to maintain an open and collaborative relationship.

Although MOH often develops outside of GPs' immediate view through patients' self-medication, GPs are important in its prevention, detection, and treatment. The first step is educating patients, and when they do not understand the cause of and treatment for $\mathrm{MOH}$, taking time to inform them and clarify their misunderstandings. ${ }^{29}$ The next step is to develop a plan with the patient and provide clear and continuing support for what is often a challenging journey. General practitioners also need to be aware of situations in which patients should be referred to a neurologist, preferably one who specialises in headache management.

Discussions between GPs or pharmacists and patients who overuse headache medication are often 
delicate. The patient may perceive an accusation of 'recreational use' of (particularly codeine-containing) drugs. It is vital for productive communication that the health care professional clarify that there is no suspicion of this type and that the medications are recognised as being used to deal with genuinely troublesome symptoms. It is vital to subsequently emphasise that ongoing use of particular headache medications may contribute to perpetuation of headaches and that better strategies are available.

\section{Management and prevention strategies}

Prevention of headaches is better than curing them. Pharmacists and GPs who are aware of $\mathrm{MOH}$ can detect patients with increasing frequencies of headaches and medication use. Strategies to assist such patients before they progress into frank $\mathrm{MOH}$ include lifestyle adjustments and appropriate prophylaxis, as discussed below as part of $\mathrm{MOH}$ treatment (Box 2).

Complete withdrawal from overused headache medications is a key component of the management strategy, along with education, counselling, and support. Abrupt withdrawal is usually preferred, but tapered withdrawal may be more appropriate when codeine is implicated. ${ }^{25}$ Coexisting psychiatric conditions should also be assessed and managed. As medication discontinuation results in withdrawal headaches-often associated with nausea, vomiting, and sleep disturbance-patients frequently need assistance coping with withdrawal symptoms and persevering with discontinuation. ${ }^{4,12,33,34}$ Symptoms usually last between 2 and 10 days, with withdrawal

BOX 2. Treatment strategies for patients with $\mathrm{MOH}$ (abrupt withdrawal with immediate initiation of prophylactic medication)

\footnotetext{
1. Introduce appropriate migraine prophylaxis

- Topiramate

- Antidepressants (eg, amitriptyline)

- Onabotulinum toxin A

- Drugs used for episodic migraines (eg, beta blockers)
}

2. Provide education on $\mathrm{MOH}$ and expected withdrawal symptoms

3. Use a staged approach to acute headache treatments

- Use NSAIDs or simple analgesics for mild headaches

- Use triptans for more severe headaches (but not $>10$ days per month)

- Avoid using codeine!

4. Use a multidisciplinary team

- Counselling

- Physiotherapy

5. Monitor progress by:

- counting headache days (please refer to Box 1 )

- counting medication days (please refer to Box 1)

6. Offer regular follow-up and support through GPs or headache nurses

7. Collaborate with local community pharmacies where feasible

Abbreviations: GPs = general practitioners; $\mathrm{MOH}$ = medication overuse headache; NSAIDs = nonsteroidal anti-inflammatory drugs from triptans lasting approximately 4 days and that from nonsteroidal anti-inflammatory drugs lasting about 10 days. Withdrawal can be managed through primary care; however, opioid discontinuation may require hospitalisation. ${ }^{34,35}$

Accurate diagnosis based on the third edition of the International Classification of Headache Disorders ${ }^{17}$ and referral of complex cases to a neurologist/headache specialist is recommended for individualised treatments. Psychiatric assessment may also be indicated in some cases. However, in many countries, limited specialist availability means that referrals need to be selective. Psychologists and physical therapists have a role, as psychotherapy, relaxation techniques, physical exercise, and cognitive behaviour therapy may be useful adjuncts to supervised pharmacotherapy. $4,12,23,28,34,36,37$ The combination of behavioural treatment and prophylactic medication may significantly reduce the risk of relapse. ${ }^{37}$ Preventive medications for chronic migraines include antiepileptic drugs (particularly topiramate), antidepressants (eg, amitriptyline), onabotulinum toxin $\mathrm{A}$, and drugs used for episodic migraines (eg, beta blockers). For example, topiramate (oral) and onabotulinum toxin A (by local injection) are recommended by the Taiwan Headache Society 2017 medical treatment guidelines as first-line treatments for prophylaxis of chronic migraines..$^{38}$ Education about acute and prophylactic treatment may improve adherence to both pharmacological and non-pharmacological therapies. ${ }^{28}$

In some circumstances, withdrawal may require hospital admission. Patients with $\mathrm{MOH}$ who have been detoxified as in-patients should be followed up by their GPs. Support by a headache nurse (available in some neurological practices) can improve adherence to detoxification. ${ }^{39}$

Multidisciplinary treatment of patients with $\mathrm{MOH}$, including pharmacological prophylaxis, relaxation therapy, and aerobic sports, is associated with reduction in headaches, as long as patients adhere to the recommended therapies. ${ }^{28}$ Motivational telephone interviewing may also help to promote adherence..$^{40}$ To supplement regular GP support, practice nurses could be involved in patient support, and they could liaise with pharmacists to monitor medication use.

\section{Conclusion}

There is an urgent need for increased awareness of $\mathrm{MOH}$ among both patients and health care professionals. ${ }^{41}$ Medication overuse headache causes considerable morbidity but is preventable. Headache frequency (and the associated disability, depression, and anxiety) can be considerably reduced in patients with $\mathrm{MOH}$ through withdrawal from the overused medication and appropriate supportive treatment. 
A multidisciplinary approach involving primary care physicians (GPs), community pharmacists, nurses, and allied health providers, ${ }^{36}$ with referral to neurologists/headache specialists (where available) for complex cases, is recommended.

\section{Author contributions}

All authors contributed to the concept of the paper, acquisition and interpretation of data and critical revision of the manuscript for important intellectual content. EA and MVD drafted the article. All authors approved the final version.

\section{Declaration}

M van Driel, T McGuire, and R Stark have received consulting fees from In Vivo Academy Ltd for development of education materials for a multidisciplinary programme about $\mathrm{MOH}$. In Vivo Academy Ltd received an unrestricted educational grant from Pfizer to develop educational material about $\mathrm{MOH}$. $\mathrm{R}$ Stark has also received lecture and/or consulting fees from Allergan, Novartis, TEVA, MSD, Abbvie and SciGen (Australia) and from In Vivo Academy Ltd relating to a Pfizersponsored project, and has undertaken clinical trials for Allergan. E Anderson is an employee of In Vivo Academy Ltd.

\section{References}

1. Cha MJ, Moon HS, Sohn JH, et al. Chronic daily headache and medication overuse headache in first-visit headache patients in Korea: a multicenter clinic-based study. J Clin Neurol 2016;12:316-22.

2. Cheung V, Amoozegar F, Dilli E. Medication overuse headache. Curr Neurol Neurosci Rep 2015;15:509.

3. Herekar AA, Ahmad A, Uqaili UL, et al. Primary headache disorders in the adult general population of Pakistan-a cross sectional nationwide prevalence survey. J Headache Pain 2017;18:28.

4. Kristoffersen ES, Lundqvist C. Medication-overuse headache: epidemiology, diagnosis and treatment. Ther Adv Drug Saf 2014;5:87-99.

5. Steiner TJ, Stovner LJ, Katsarava Z, et al. The impact of headache in Europe: principal results of the Eurolight project. J Headache Pain 2014;15:31.

6. Yu S, Liu R, Zhao G, et al. The prevalence and burden of primary headaches in China: a population-based door-todoor survey. Headache 2012;52:582-91.

7. Westergaard ML, Munksgaard SB, Bendtsen L, Jensen RH. Medication-overuse headache: a perspective review. Ther Adv Drug Saf 2016;7:147-58.

8. Zebenholzer K, Andree C, Lechner A, et al. Prevalence, management and burden of episodic and chronic headaches-a cross-sectional multicentre study in eight Austrian headache centres. J Headache Pain 2015;16:531.

9. Dong Z, Chen X, Steiner TJ, et al. Medication-overuse headache in China: clinical profile, and an evaluation of the ICHD-3 beta diagnostic criteria. Cephalalgia 2015;35:64451.

10. Manandhar K, Risal A, Steiner TJ, Holen A, Linde M. The prevalence of primary headache disorders in Nepal: a nationwide population-based study. J Headache Pain 2015;16:95.

11. Johnson JL, Hutchinson MR, Williams DB, Rolan P.
Medication-overuse headache and opioid-induced hyperalgesia: A review of mechanisms, a neuroimmune hypothesis and a novel approach to treatment. Cephalalgia 2013;33:52-64.

12. Smith TR, Stoneman J. Medication overuse headache from antimigraine therapy: clinical features, pathogenesis and management. Drugs 2004;64:2503-14.

13. Bøe MG, Salvesen R, Mygland A. Chronic daily headache with medication overuse: predictors of outcome 1 year after withdrawal therapy. Eur J Neurol 2009;16:705-12.

14. Butler J. You won't be able to buy codeine over the counter anymore. Huffington Post 2016 Dec 20. Available from: http://www.huffingtonpost.com.au/2016/12/19/ you-wont-be-able-to-buy-codeine-over-the-counteranymore_a_21631170/. Accessed 25 Oct 2018.

15. Therapeutic Goods Administration, Department of Health, Australian Government. Proposal for the re-scheduling of codeine products. 2015. Available from: https://www.tga. gov.au/media-release/proposal-re-scheduling-codeineproducts. Accessed 2 Mar 2017.

16. Roxburgh A, Hall WD, Burns L, et al. Trends and characteristics of accidental and intentional codeine overdose deaths in Australia. Med J Aust 2015;203:299.

17. GBD 2015 Neurological Disorders Collaborator Group. Global, regional, and national burden of neurological disorders during 1990-2015: a systematic analysis for the Global Burden of Disease Study 2015. Lancet Neurol 2017;16:877-97.

18. Headache Classification Committee of the International Headache Society. The International Classification of Headache Disorders, 3rd edition (beta version). Cephalalgia 2013;33:629-808.

19. van Driel ML, McGuire TM, Stark R, Lazure P, Garcia $\mathrm{T}$, Sullivan L. Learnings and challenges to deploy an interprofessional and independent medical education programme to a new audience. J Eur CME 2017;6:1400857.

20. Khu JV, Siow HC, Ho KH. Headache diagnosis, management and morbidity in the Singapore primary care setting: findings from a general practice survey. Singapore Med J 2008;49:774-9.

21. Ong JJ, Chan YC. Medical undergraduate survey on headache education in Singapore: knowledge, perceptions, and assessment of unmet needs. Headache 2017;57:96778.

22. Lipton RB, Dodick D, Sadovsky R, et al. A self-administered screener for migraine in primary care: The ID MigraineTM validation study. Neurology 2003;61:375-82.

23. Frich JC, Kristoffersen ES, Lundqvist C. GPs' experiences with brief intervention for medication-overuse headache: a qualitative study in general practice. Br J Gen Pract 2014;64:e525-31.

24. Katsarava Z, Muessig M, Dzagnidze A, Fritsche G, Diener HC, Limmroth V. Medication overuse headache: rates and predictors for relapse in a 4-year prospective study. Cephalalgia 2005;25:12-5.

25. Evers S, Marziniak M. Clinical features, pathophysiology, and treatment of medication-overuse headache. Lancet Neurol 2010;9:391-401.

26. Scher AI, Rizzoli PB, Loder EW. Medication overuse headache: an entrenched idea in need of scrutiny. Neurology 2017;89:1296-304.

27. Carlsen LN, Munksgaard SB, Jensen RH, Bendtsen L. Complete detoxification is the most effective treatment of 
medication-overuse headache: a randomized controlled open-label trial. Cephalalgia 2018;38:225-36.

28. Gaul C, Brömstrup J, Fritsche G, Diener HC, Katsarava Z. Evaluating integrated headache care: a one-year followup observational study in patients treated at the Essen headache centre. BMC Neurol 2011;11:124.

29. Giaccone M, Baratta F, Allais G, Brusa P. Prevention, education and information: the role of the community pharmacist in the management of headaches. Neurol Sci 2014;35(1 Suppl):1-4.

30. O'Sullivan EM, Sweeney B, Mitten E, Ryan C. Headache management in community pharmacies. Ir Med J 2016;109:373.

31. Naito Y, Ishii M, Kawana K, Sakairi Y, Shimizu S, Kiuchi Y. Role of pharmacists in a community pharmacy for self-medication of patients with headache [in Japanese]. Yakugaku Zasshi 2009;129:735-40.

32. Naito Y, Ishii M, Sakairi Y, Kawana K, Shimizu S, Kiuchi Y. Need for collaboration between community pharmacies and hospitals or clinics in providing medical treatment for patients with headache [in Japanese]. Yakugaku Zasshi 2009;129:741-8.

33. Stark R, Hutton E. Chronic migraine and other types of chronic daily headache. Medicine Today 2013;14:29-35.

34. Kristoffersen ES, Lundqvist C. Medication-overuse headache: a review. J Pain Res 2014;26:367-78.

35. Williams D. Medication overuse headache. Aust Prescr 2005;28:59-62.

36. Bendtsen L, Munksgaard S, Tassorelli C, et al. Disability, anxiety and depression associated with medication-overuse headache can be considerably reduced by detoxification and prophylactic treatment. Results from a multicentre, multinational study (COMOESTAS project). Cephalalgia 2014;34:426-33.

37. Lake AE 3rd. Medication overuse headache: biobehavioral issues and solutions. Headache 2006;46(3 Suppl):S88-97.

38. Huang TC, Lai TH, Taiwan Headache Society TGSOTHS. Medical treatment guidelines for preventive treatment of migraine. Acta Neurol Taiwan 2017;26:33-53.

39. Pijpers JA, Louter MA, de Bruin ME, et al. Detoxification in medication-overuse headache, a retrospective controlled follow-up study: does care by a headache nurse lead to cure? Cephalalgia 2016;36:122-30.

40. Stevens J, Hayes J, Pakalnis A. A randomized trial of telephone-based motivational interviewing for adolescent chronic headache with medication overuse. Cephalalgia 2014;34:446-54.

41. Stark R, McGuire T, van Driel M. Medication overuse headache in Australia: a call for multidisciplinary efforts at prevention and treatment. Med J Aust 2016;205:283. 